\title{
Randomized controlled clinical trial comparing one-piece and two-piece dental implants supporting fixed and removable dental prostheses: 4- to 6-year observations
}

Gamper, Felix B ; Benic, Goran I ; Sanz-Martin, Ignacio ; Asgeirsson, Asgeir G ; Hämmerle, Christoph H F ; Thoma, Daniel S

\begin{abstract}
OBJECTIVES To test whether or not a one- (S1) and a two-piece (S2) dental implant systems render the same biological, technical, and esthetic outcomes regarding implants and implant-supported reconstructions over an observation period of 4 to 6 years. MATERIALS AND METHODS Sixty patients were randomly assigned to receive S1 or S2 implants. The implants were restored with either fixed or removable prostheses. The insertion of the final reconstruction was chosen as baseline. One-year and 4- to 6-year (FU-5) measurements included biological (e.g. marginal bone level, probing pocket depth, peri-implant mucositis, and peri-implantitis), technical (e.g. fracture or loosening of prosthetic screws, fracture or loosening of abutments, fracture of framework, and/or veneering ceramic (minor, major), loss of retention for cemented restorations), and esthetic parameters (visibility of the crown margin, shimmering of the implant through the mucosa, the level of the facial margo mucosae compared to the contralateral tooth or implant site and the modified papilla index) for implants and reconstructions. Survival and success rates of implants and reconstructions were calculated. Because of the asymmetric data distributions, nonparametric statistical methods were applied. RESULTS The implant-based analysis revealed a cumulative implant survival rate of $97.9 \%$ (S1: 96.6\%; S2: 98.9\%) at FU-5. The median marginal bone level for group S1 changed from $0.51 \mathrm{~mm}$ at baseline to $0.49 \mathrm{~mm}$ at FU-5 and for group S2 from $1.02 \mathrm{~mm}$ to $1.35 \mathrm{~mm}(\mathrm{P}$ $<0.001$ ). Patient-level analyses demonstrated a frequency of peri-implant mucositis of 7.7\% (S1) and 10.0\% (S2) and for peri-implantitis of $7.7 \%$ (S1) and $13.3 \%$ (S2) at FU-5. The patient-based cumulative implant survival rate was $94.6 \%$ (S1: 92.3\%; S2: 96.7\%). The overall patient-based biological complication rate amounted to $15.4 \%$ (S1) and to $23.3 \%(\mathrm{~S} 2)(\mathrm{P}=0.517)$, whereas the overall technical complication rates were $30.8 \%(\mathrm{~S} 1)$ and $13.3 \%(\mathrm{~S} 2)(\mathrm{P}=$ 0.349). The prosthetic survival rates were $93.1 \%$ for $\mathrm{S} 1$ and $100 \%$ for $\mathrm{S} 2(\mathrm{P}>0.05)$. CONCLUSIONS Both implant systems reveal high survival rates on the implant and prosthetic level. Apart from marginal bone-level changes, biological and technical outcomes did not reveal significant differences between the two implant systems.
\end{abstract}

DOI: https://doi.org/10.1111/clr.13025

Posted at the Zurich Open Repository and Archive, University of Zurich

ZORA URL: https://doi.org/10.5167/uzh-139614

Journal Article

Accepted Version

Originally published at:

Gamper, Felix B; Benic, Goran I; Sanz-Martin, Ignacio; Asgeirsson, Asgeir G; Hämmerle, Christoph H F; Thoma, Daniel S (2017). Randomized controlled clinical trial comparing one-piece and two-piece dental implants supporting fixed and removable dental prostheses: 4- to 6-year observations. Clinical Oral Implants Research, 28(12):1553-1559. 
DOI: https://doi.org/10.1111/clr.13025 


\section{Randomized controlled clinical trial comparing one-piece and two-piece dental implants supporting fixed and removable dental prostheses: 4- to 6-year observations}

Felix B. Gamper ${ }^{1}$, Goran I. Benic ${ }^{1}$, Ignacio Sanz Martin ${ }^{2}$, Asgeir G. Asgeirsson ${ }^{1,3}$, Christoph H.

F. Hämmerle ${ }^{1}$, Daniel S. Thoma ${ }^{1}$

1 Clinic of Fixed and Removable Prosthodontics and Dental Material Science, Center for Dental Medicine, University of Zurich, Zurich, Switzerland

2 Section of Periodontology, Faculty of Odontology, University Complutense of Madrid, Madrid, Spain

3 University of Iceland, Faculty of Odontology, Reykjavik, Iceland

Key words: "dental implants", "humans", "crown", "fixed, partial, denture", "removable denture", "survival", "radiographic", "longterm", "complications", "comparison"

Running title: long-term study comparing two implant systems

Number of figures: 0

Number of tables: 4

Word count: 4'200

Address for correspondence: PD Dr. Daniel S. Thoma

Clinic of Fixed and Removable Prosthodontics and Dental Material Science

Center of Dental Medicine, University of Zurich

Plattenstrasse 11

$\mathrm{CH}-8032$ Zurich, Switzerland

Phone: +4116343252

Fax: +4116344305

e-mail: daniel.thoma@zzm.uzh.ch 


\section{Abstract}

Objectives: To test whether or not a one- (S1) and a two-piece (S2) dental implant system render the same biological, technical and esthetic outcomes regarding implants and implantsupported reconstructions over an observation period of 4 to 6 years.

Materials and methods: Sixty patients were randomly assigned to receive S1 or S2 implants. The implants were restored with either fixed or removable prostheses. The insertion of the final reconstruction was chosen as baseline. One-year and 4- to 6-year (FU-5) measurements included biological (e.g. marginal bone level, probing pocket depth, peri-implant mucositis and peri-implantitis), technical (e.g. fracture or loosening of prosthetic screws, fracture or loosening of abutments, fracture of framework and/or veneering ceramic (minor, major), loss of retention for cemented restorations) and esthetic parameters (visibility of the crown margin, shimmering of the implant through the mucosa, the level of the facial margo mucosae compared to the contralateral tooth or implant site and the modified papilla index) for implants and reconstructions. Survival and success rates of implants and reconstructions were calculated. Because of the asymmetric data distributions, nonparametric statistical methods were applied.

Results: The implant-based analysis revealed a cumulative implant survival rate of $97.9 \%$ (S1: $96.6 \% ; \mathrm{S} 2: 98.9 \%$ ) at FU-5. The median marginal bone level for group S1 changed from $0.51 \mathrm{~mm}$ at baseline to $0.49 \mathrm{~mm}$ at FU-5 and for group S2 from $1.02 \mathrm{~mm}$ to $1.35 \mathrm{~mm}(\mathrm{p}<0.001)$. Patient-level analyses demonstrated a frequency of peri-implant mucositis of $7.7 \%(\mathrm{~S} 1)$ and $10.0 \%(\mathrm{~S} 2)$ and for peri-implantitis of $7.7 \%(\mathrm{~S} 1)$ and $13.3 \%(\mathrm{~S} 2)$ at FU-5. The patient-based cumulative implant survival rate was $94.6 \%$ (S1: 92.3\%; S2: 96.7\%). The overall patientbased biological complication rate amounted to $15.4 \%(\mathrm{~S} 1)$ and to $23.3 \%(\mathrm{~S} 2)(\mathrm{p}=0.517)$, whereas the overall technical complication rates were $30.8 \%(\mathrm{~S} 1)$ and $13.3 \%(\mathrm{~S} 2)(\mathrm{p}=0.349)$. The prosthetic survival rates were $93.1 \%$ for S1 and $100 \%$ for S2 ( $>>0.05)$.

Conclusions: Both implant systems reveal high survival rates on the implant and prosthetic level. Apart from marginal bone level changes, biological and technical outcomes did not reveal significant differences between the two implant systems. 


\section{Introduction}

The use of dental implants is considered a predictable therapeutic option for the rehabilitation of partially or fully edentulous patients providing long-term function and esthetics (Chappuis et al. 2013; Jung et al. 2012; Pjetursson et al. 2012b). The indication spectrum includes various prosthetic reconstructions of either fixed or removable nature. Since their development in the early 1970s (Adell et al. 1970; Branemark et al. 1969a; Branemark et al. 1971; Schroeder et al. 1976; Schroeder et al. 1978) the promising long-term data of dental implants (Adell et al. 1981; Branemark et al. 1977a; Buser et al. 1997; Merickse-Stern et al. 2001) resulted in an increasing number of implant systems with different designs and surfaces on the market. In general, two main types of dental implant designs are distinguished: one-piece and two-piece implants. One-piece implants are characterized by a rough body for intraosseous placment and a machined collar, the latter part ermerging through the soft tissues (Scacchi 2000; Scacchi et

al. 2000). Two-piece dental implants were originally designed for submerged healing. Submerging appears to reduce initial bone resorption after implant placement (Ericsson et al. 1996; Ericsson et al. 1994). A second surgical intervention (abutment connection) (Branemark et al. 1969b; Branemark et al. 1977b) then becomes necessary, however, to connect the prosthesis to the implant. Following this second-stage procedure, remodeling of the marginal bone takes place (Belser et al. 1998; Esposito et al. 1993; Tarnow et al. 2003). Both types of implants have been used for years and long-term data demonstrate high survival rates (Derks et al. 2015). Apart from survival rates, the number of complications on the implant and the prosthetic level is of high interest for both clinicians and patients alike. In systematic reviews (Jung et al. 2012; Pjetursson et al. 2012b) complication rates have been shown in a range of 3.58.8\% (technical), $2.6-8.5 \%$ (biological) and 3.6-13-6\% (esthetic). Today, it is unknown whether the general design differences between one- and two-piece dental implants affect the long-term rates of technical, biological and esthetic complications. There are few clinical studies comparing different implant systems, such as one- versus two-piece implants (Astrand et al. 1999; Meijer et al. 2004; Moberg et al. 2001; Pinholt 2003; Thoma et al. 2014). Moreover, the literature is scarce in terms of randomized controlled clinical trials (RCTs) comparing different implant systems (Esposito et al. 2005). In a systematic review, only four RCTs fulfilled 
the inclusion criteria and reported on a total of 204 patients. It was concluded that there is no strong evidence supporting the superiority of one implant system over others. It is important to note that this review was based on a few RCTs, evaluating few implant systems in few patients. Hence, a clear need was stated for more long-term studies comparing different implant systems.

The aim of the present clinical trial was, therefore, to test whether or not a one- (S1) and a two-piece (S2) dental implant system render the same biological, technical and esthetic outcomes regarding implants and implant-supported reconstructions over an observation period of 4 to 6 years. 


\section{Materials and methods}

The study was designed as a randomized controlled clinical trial and approved by the local ethical committee as a long-term non-interventional study (KEK-ZH-Nr 2014-0201). The specific protocol and inclusion criteria were described in a previous publication (Thoma et al. 2014). In brief, sixty partially or fully edentulous patients (S1: 13 males and 17 females; S2: 10 males and 20 females) in need of implant therapy were consecutively included and randomly allocated to one of the two groups using a computer-generated randomization list. Exclusion criteria were general contraindications for implant therapy (systemic or local diseases) and patients not fulfilling the inclusion criteria (medically healthy and older than 18 years). Patients signed an informed consent and were, according to a computer-generated list, randomly assigned to receive one-piece (Straumann Tissue Level Implants, Institut Straumann, Basel, Switzerland; S1) or two-piece dental implants (Brånemark MkIII or MkIV, Nobel Biocare, Zurich, Switzerland; S2). All implant surgeries were performed according to the manufacturer's guidelines. S1 implants were placed with the transition between the rough and smooth surface at the bone crest and S2 implants with the flat top at the bone crest. Some implants were placed with increased sink depth below the bone crest if necessary for prosthetic reasons. The majority of the implants in both groups received a bone augmentation procedure (Details in Table 1). Subsequently, implants were subjected to a submerged or transmucosal healing irrespective of the implant design (one- or two-piece implant). The type of healing was dependent on the location and whether or not bone augmentation procedures were performed.

\section{Baseline and follow-up examinations}

The insertion of the final reconstruction (between 2004 and 2008) was chosen as baseline and patients were subsequently enrolled in an individually designed maintenance program with periodic visits to the dental hygienist. The dental hygiene sessions were performed either at the Clinic of Fixed and Removable Prosthodontics and Dental Material Science, University of Zurich, Switzerland or in private practices. At baseline, the mean age for patients with S1 was 47.5 years (standard deviation $(S D) \pm 15$ ) and 55.8 years $( \pm 14)$ for the S2 group. All 151 implants (S1: 65; S2: 86) were inserted between 2002 and 2005. A total of 14 patients reported smoking habits: 9 patients in the S1 group ( 2 patient $<5$ cigs/day; 7 patients $>5$ 
cigs/day) and 5 patients in the S2 group ( 1 patient $<5$ cigs/day; 4 patients $>5$ cigs/day). Only three patients (1 in S1, 2 in S2) reported habits of bruxism. The differences with regards to smoking and bruxism were not significant between the two groups (Thoma et al. 2014). Implant length and implant diameter were recorded and no significant differences were found between the two groups ( $p=0.157, p=0.144$ respectively).

All sixty patients, however, were recalled for the follow-up examinations at one year and again at 4 to 6 years (FU-5) following the insertion of the final reconstruction at the Clinic of Fixed and Removable Prosthodontics and Dental Material Science, University of Zurich, Switzerland.

\section{Outcome measures}

The following biological, technical and esthetic parameters were assessed at baseline, one year and at 4 to 6 years:

Biological outcome measures: A full-mouth periodontal status was recorded in each patient. This included probing pocket depth (PPD) (Ramfjord 1974), clinical attachment level (CAL), plaque control record (PCR) (O'Leary et al. 1972), and bleeding on probing (BOP) (Ainamo \& Bay 1975). All measurements were recorded at 6 sites per tooth and implant using a UNC-15 periodontal probe (Hu-Friedy, Chicago, IL, USA). In addition, the width of the keratinized mucosa was measured at the buccal aspect of all implants. Intraoral radiographs were taken using a paralleling technique with standardized rim-holders and analog films (Kodak Ektaspeed Plus, Eastman Kodak Co., Rochester, NY, USA). After digital scanning of the x-rays, x-rays taken at the different time points of assessment were compared and changes of the marginal bone level over time were calculated using an open-source software (Image J, National Institutes of Health, Bethesda, Maryland USA) For calibration purposes the distance between two implant threads and the determination of the exact magnification of the images was used. The reference point of the two-piece implant (S2) was the most coronal point of the flat top of the implant. At the one-piece implant (S1), the implant shoulder served as reference point for the measurements. The marginal bone level was assessed at the mesial and distal implant surfaces by measuring the distance from the reference point of the implant to the first bone-toimplant contact (fBIC). For S1 implants, the expected bone level was at the transition between the rough and smooth surface. Therefore, $1.8 \mathrm{~mm}$ (height of smooth collar) was deducted from 
all fBIC values. For S2 implants, the bone level was expected at the flat top. No correction of fBIC values was therefore performed for S2 implants (Astrand et al. 2002).

In addition, the incidence of biological complications was documented in the patient records and at the follow-up examinations. This included: peri-implant mucositis (clinical signs of inflammation without crestal bone loss, probing pocket depth $\geq 5 \mathrm{~mm}$ and bleeding on probing at $>50 \%$ of the sites at a given implant) and peri-implantitis (mucositis in conjunction with crestal bone loss $\geq 2 \mathrm{~mm}$ ). (Mombelli \& Lang 1994)

Technical outcome measures: All technical complications such as implant fracture, fracture or loosening of prosthetic screws, fracture or loosening of abutments, fracture of framework and/or veneering ceramic (minor, major), loss of retention for cemented restorations or loosening of screw access hole restorations were continuously documented in the patient records and at the follow-up examinations.

Esthetic and further outcome measures: The following additional parameters were recorded: visibility of the crown margin (yes or no), shimmering of the implant through the mucosa (yes or no), the level of the peri-implant margo mucosae compared to the contralateral tooth or implant site (similar, positive/negative (margo of implant site more coronal/apical) than contralateral site), and the modified papilla index (Jemt 1997).

Moreover, biological and technical complications as well as survival rates of implants and reconstructions were calculated at FU-5. Survival was defined as remaining in situ and in function regardless of therapeutical interventions during the observation period.

\section{Statistical analysis:}

All data were recorded in Microsoft Excel spreadsheets (Microsoft Corporation, Redmond, WA, USA). For the descriptive part of the paper median, quartiles, mean and standard deviation were computed on implant-based data. Due to the fact that the generated data were asymmetric and showed statistical outliers, the authors decided to report medians with quartiles in the text. Because of the same reasons, nonparametric mixed models were used for the patient-level analysis. The rates were compared with Fisher exact test and the corresponding $95 \%$ confidence intervals were derived using the Binomial distribution. Data were analyzed 
with SAS 9.4 (SAS Institute Inc., Cary, NC, USA). 


\section{Results}

\section{Demographic data:}

Originally, 60 patients were treated with 151 dental implants. The prosthetic reconstructions were removable (17 of the implants), screw-retained (103 of the implants) or cemented (31 of the implants). In total, a number of 93 fixed and 6 removable prostheses were placed. A detailed overview of the prosthetic reconstructions are reported in Table 1 . The overall mean implant length was $11.2 \mathrm{~mm}(\mathrm{~S} 1: 11.5 \pm 1.7 \mathrm{~mm}$; S2: $10.7 \pm 1.6 \mathrm{~mm})$, whereas the mean implant diameter was $4.1 \mathrm{~mm}(\mathrm{~S} 1: 4.0 \pm 0.3 \mathrm{~mm}, \mathrm{~S} 2: 4.2 \pm 0.0 \mathrm{~mm})$. Details related to the distribution of the implants in the oral cavity are listed in a previous publication (Thoma et al. 2014).

The median follow-up time was 5.0 years (Q1: 4.7 ; Q3: 5.2 ; range $4.2-6.4$ years) and the mean age of the patients 52.7 years $( \pm 15)$ for group S1 and 60.8 years $( \pm 14)$ for group S2. One male patient and three female patients with a total number of 6 implants (all in group S1) were recorded as drop-outs $(6.7 \%)$. The reasons for the drop-out were due to a cancerinduced resection of the whole upper jaw (1 patient; 2 implants; cement-retained cantilevered splinted single crowns; S1), inability to travel to the study clinic due to patient's relocation (1 patient; 2 implants; cement-retained splinted single crowns; S1) or failure to contact the patients (2 patients; 2 implants; screw-retained single crowns; S1) (Table 1).

\section{Survival rates:}

During the observation period a total number of three implants were lost. All of them had to be explanted because of progressive bone-loss and peri-implant disease, two SCs in group S1 (in two different patients), one two-unit FDP on two implants (2FDP) in group S2. Overall, the cumulative implant-based survival rate was therefore $97.9 \%$ (142 out of 145 implants) at FU-

5. Splitting the two groups, the survival rates changed to $96.6 \%$ ( $57 / 59$ implants) for $\mathrm{S} 1$ and $98.9 \%$ (85/86 implants) for S2.

On the patient-level, the overall cumulative implant survival rate was $94.6 \%(53 / 56)$ at FU-5. Calculated for group S1 (24/26), the survival rate was $92.3 \%$ (95\% c.i. $(77 \%, 99 \%))$ and $96.7 \%(95 \%$ c.i. $(84 \%, 99.9 \%))$ for group S2 (29/30). The survival rates of S1 and S2 did not differ significantly $(p=0.592)$. 


\section{Radiographic outcomes:}

On the implant level, the median marginal bone level at baseline was $0.51 \mathrm{~mm}$ (Quartiles (Q): $0.14 ; 0.96)$ for $\mathrm{S} 1$ and $1.02 \mathrm{~mm}(\mathrm{Q}: 0.82 ; 1.23)$ for $\mathrm{S} 2$. At FU-5, the median marginal bone level was $0.49 \mathrm{~mm}(\mathrm{Q}: 0.16 ; 0.93)$ for $\mathrm{S} 1$ and $1.35 \mathrm{~mm}(\mathrm{Q}: 1.12 ; 1.63)$ for $\mathrm{S} 2$ (Table $2 \mathrm{~A})$. The intergroup patient based analysis (S1 vs. S2) revealed no significant differences in terms of marginal bone levels at baseline $(p=0.0722)$ and significant differences in favor of group S1 at FU$5(p=0.0014)$ (Table $2 B)$. The intra-group patient-based analysis revealed statistically significant differences of the marginal bone-level changes between baseline and FU-5 for group S2 $(p=0.0002)$, but not for group $S 1(p=1.00)$ (Table $2 C)$. The inter-group comparison for changes between baseline and FU-5 was statistically significantly different between S1 and S2 $(p<0.001)$

\section{Biological outcomes:}

Except for peri-implantitis, all parameters measured (PPD, PCR, BOP and the width of the keratinized mucosa) were similar for both groups and at both time-points (Table 3). Over the observation period, the number of implants diagnosed with peri-implant mucositis was $3 / 57$ (5.3\%) in 2 patients for S1 and $9 / 85(10.6 \%)$ in 3 patients for S2. Six out of 9 implants diagnosed with peri-implant mucositis in group S2 were in the same patient, treated with a barretained hybrid prosthesis. On the patient-level, the rate for peri-implant mucositis was $7.7 \%$ (95\% c.i. $(1 \%, 23 \%))$ for group S1 $(2 / 26)$ and $10.0 \%(95 \%$ c.i. $(3 \%, 25 \%))$ for group S2 $(3 / 30)$ up to $\mathrm{FU}-5$. These rates between the two groups did not differ significantly $(p=1.00)$.

The number of implants affected by peri-implant disease was $4 / 57$ (7.0\%) for $S 1$ and $7 / 86$ $(8.1 \%)$ for S2. In group S1, only two patients were affected (one patient, two implants; one patient, two implants). In group S2 and 7 implants in four patients were diagnosed with periimplantitis (one patient, one implant; one patient, one implant; one patient, two implants; one patient, three implants). These implants showing progressive bone loss and were treated according to a standard protocols both non-surgically and surgically. On the level of the patient, the cumulative rate for peri-implantitis was $10.7 \%(6 / 56), 7.7 \%(95 \%$ c.i. $(1 \%, 23 \%))$ for group S1 $(2 / 26)$ and $13.3 \%(95 \%$ c.i. $(5 \%, 29 \%))$ for group S2 $(4 / 30)(p=0.675)$ at FU-5. 
The patient-based analysis revealed a total biological complication rate of $19.6 \%(11 / 56)$, resulting in $15.4 \%(95 \%$ c.i. $(5 \%, 33 \%))$ for S1 $(4 / 26)$ and in $23.3 \%$ (95\% c.i. $(10 \%, 41 \%))$ for $\mathrm{S} 2(7 / 30)(p=0.517)$.

\section{Technical outcomes:}

During a median observation period of 5 years, 23 out of 145 implants demonstrated a total number of 30 technical complications. Twenty-two of the 27 affected implants were in group S1 showing $83.3 \%(25 / 30)$ of all technical complications in the present study. This included for group S1: 8 matrices having been renewed (2/8 in the same patient/same implant; 5/8 in the same patient on 5 different implants; $1 / 8$ in one patient, one implant), 10 screw loosenings (1/10 in one patient, one implant; $2 / 10$ in one patient, one implant; $3 / 10$ in one patient, three implants; $4 / 10$ in one patient, four implants), 4 minor chippings (2/4 in one patient, two implants; $2 / 4$ in one patient, two implants) and three times a loss of the screw access hole restorations (in one patient, three implants). The patient-based analysis revealed a total technical complication rate of $34.6 \%$ (95\% c.i. $(17.2 \%, 55.7 \%)$ ) for S1 $(9 / 26)$. In group S2, five implants showed five technical complications, which resulted in $19.2 \%(5 / 26)$ of all reported complications. This included: three minor chippings (2/3 in one patient, two implants; $1 / 3$ in one patient, one implant), 1 major chipping (one patient, one implant) and 1 loss of the screw access hole restoration (one patient, one implant). The patient-based analysis revealed a total technical complication rate of $13.3 \%(95 \%$ c.i. $(5 \%, 29 \%))$ for S2 $(4 / 30)$. The patient-based rates of the two groups were not significantly different $(p=0.349)$.

In both groups, no implant fractures, fractures of the prosthetic screws, fractures of the abutments or fractures of the frameworks occurred. In group S1 two reconstructions had to be renewed. One due to a major chipping, one due to the loss of the abutment tooth wearing a tooth-implant supported prostheses.

These findings resulted in a cumulative implant-based survival rate of the prosthetic reconstructions of $96.6 \%$ (140 out of 145 implants), divided in $93.2 \%$ (55 out of 59 implants) for S1 and $98.9 \%$ (85 out of 86 implants) for S2. 
Based on the patient-level the cumulative survival rate of the prosthesis was $96.4 \%(54 / 56)$. $92.3 \%(95 \%$ c.i. $(77 \%, 99 \%))$ of the reconstructions survived in group S1 $(24 / 26)$ and $100 \%$ $(95 \%$ c.i. $(90 \%, 100 \%))$ survived in group S2 $(30 / 30)(p=0.211)$.

\section{Esthetic and further outcome measures:}

In group S1, a modified papilla index with values $\leq 2$ was found in 32 implants at 1 year and in 24 implants at FU-5 (S2: 37 and 59 implants, respectively). The peri-implant mucosal margin was located more apical compared to the contralateral tooth site in 22 implants at 1 year and in 30 implants at FU-5 (group S1). In group S2, the respective number of implants was 22 at 1 year and 42 at FU-5. A shimmering of the implant through the mucosa was observed at 6 and 12 implant sites (at 1 year and at FU-5) in group S1. The respective number of implants in group S2 was 12 (1 year) and 28 (FU-5). All details are displayed in Table 4. 


\section{Discussion}

The present RCT comparing two types of implant systems demonstrated: i) high implant and prosthetic survival rates without significant differences between the two implant systems up to FU-5; ii) significantly higher marginal bone levels (MBL) at FU-5 and non-significant changes of MBL from baseline to FU-5 for the one-piece dental implant system; iii) significantly lower marginal bone levels (MBL) and significant changes of MBL from baseline to FU-5 for the twopiece implant system; iv) a lower rate of biological, but a higher rate of technical complications for the one-piece compared to the two-piece implant system.

Within the present study, a high cumulative implant survival rate of $97.9 \%$ was recorded. This survival rate compares well to the $97.3 \%$ implant survival rate at a 3 -year follow-up reported in another study comparing the same two implant systems (Astrand et al. 2004). In that randomised split-mouth study in the maxilla, two-piece implants (Brånemark Implants, Nobel Biocare) were placed on one side and one-piece implants (Straumann Implants, Institut Straumann) on the contralateral side of the residual dentition. The data are further in line with two previously published systematic reviews reporting five year survival rates of $95.6 \%$ for implants supporting FDPs (Pjetursson et al. 2012b) and 97.2\% for implants supporting SCs (Jung et al. 2012).

In addition, a high prosthetic survival rate of $96.6 \%$ was found. Two previously published prospective studies evaluating the same two-piece dental implants and the respective FDPs showed estimated survival rates of the reconstructions of $96.3 \%$ (Ortorp \& Jemt 2008) and 97.0\% (Andersson et al. 2003) after observation periods of 5 years. For the one-piece dental implant system, two prospective clinical trials reported even slightly increased estimated prosthetic survival rates of $97.5 \%$ (Bragger et al. 2001) and $98.7 \%$ (Behneke et al. 2000) after observation periods of 5 years. Based on the two systematic reviews (Jung et al. 2008b; Pjetursson et al. 2012b), meta-analyses revealed a survival rate of implant-supported SCs of $94.5 \%$ and of $95.4 \%$ for implant-borne FDPs after 5 years in function. In summary, both, implant and prosthetic survival rates in the present study are in agreement with previously published prospective studies and systematic reviews. 
The marginal bone levels and bone level changes represent an indicator of osseointegration and biological success of the implant. A bone loss of $1.5 \mathrm{~mm}$ in the first year and $0.2 \mathrm{~mm}$ in every following year has previously been considered acceptable (Albrektsson et al. 1986). Thus, a bone loss of $2.3 \mathrm{~mm}(1.5+4 \times 0.2 \mathrm{~mm})$ would be considered a success at 5 years of loading. With a median bone level of $0.51 \mathrm{~mm}$ at baseline and $0.49 \mathrm{~mm}$ at FU-5 for group S1 and $1.02 \mathrm{~mm}$ at baseline and $1.35 \mathrm{~mm}$ at $\mathrm{FU}-5$ for group $\mathrm{S} 2$, the results in both groups demonstrated clinically superior results than the hitherto suggested success criteria (Albreksson et al. 1986). In the previously mentioned comparative study (Astrand et al. 2004) applying the same two implant systems, a mean marginal bone level for the one-piece implant of $1.4 \mathrm{~mm}$ at baseline and $1.3 \mathrm{~mm}$ at the 3 -year follow-up was reported. For the two-piece implant system, the marginal bone level was located $1.8 \mathrm{~mm}$ from the reference point at both timepoints. The differences observed between the present and the above-mentioned study might be due to the reference points chosen. Both studies, however, have in common that marginal bone levels demonstrate only minimal changes over time for the one-piece implant system. In the present study, the two-piece implants showed more marginal bone loss over time. It has previously been reported at the one-year follow-up of the same patient cohort (Thoma et al. 2014) that this observation might mainly be associated with two-piece implants having been placed deeper with respect to the bone crest than the one-piece implants. Similar observations, with more marginal bone loss due to greater vertical sink depth, were made in preclinical and clinical studies (Hammerle et al. 1996; Jung et al. 2008a).

In terms of further biological complications such as peri-implant mucositis or peri-implantitis, the one-piece implant system demonstrated less biological complications than the two-piece implant system. Even though, no statistically significant difference was found, group S1 showed higher percentages of both peri-implant mucositis and peri-implantitis than group S2. These data are in contrast to the findings of a previous split-mouth-study (Astrand et al. 2004). In that study, $9.1 \%$ (7/77) of the one-piece dental implants and none of the two-piece dental implants were affected by peri-implant disease. One has to bear in mind, however, that the scientific evidence is inconsistent regarding less or more biological complications for a specific implant system. Moreover, there is a lack of standardization in terms of assessing and classifying peri-implant diseases. Peri-implantitis was defined as follows in the present study: 
probing pocket depth (PPD) $\geq 5 \mathrm{~mm}$, bleeding on probing/suppuration and bone loss of $\geq 2 \mathrm{~mm}$ (Mombelli \& Lang 1994). Peri-implant mucositis was defined as probing pocket depth (PPD) $\geq 5$ $\mathrm{mm}$, bleeding on probing/suppuration without bone loss (Renvert et al. 2008). The patientbased peri-implantitis rate found in a study with 70 patients, 165 one-piece implants and a mean follow-up rate of 7.9 years, was $17.1 \%$ (Pjetursson et al. 2012a). In one of the most recent, large scale clinical analysis, 588 patients having diverse implant systems were investigated 9 years after implant therapy. The reported patient-based prevalence of moderate/severe peri-implantitis was $14.5 \%$. In terms of the odds ratios for moderate/severe periimplantitis, significantly higher incidences for patients provided with two-piece implants were observed compared to patients provided with one-piece dental implants (Derks et al. 2016).

The two implant systems differed in the extent of technical complications encountered for the fixed and removable reconstructions. Eighty-three percent of all technical complications were found in group S1, mainly including renewal of the matrices (removable prostheses) and screw-loosening of the fixed reconstructions. Taking into account the limited number of removable prostheses $(n=5)$ and the fact that all complications related to those types of reconstructions affected only three different patients (and $45.5 \%$ of the complications even the same implant), these findings have to be interpreted with caution. A comparative randomized study including the same two implant systems for the treatment of mandibular edentulism with full-arch bridges revealed more need for adjustments in the one-piece implant group during the 3-year follow-up period (Moberg et al. 2001). This is in line with the outcomes of the present study. Another prospective randomized study comparing one- and two-piece dental implants to support mandibular overdentures revealed no significant differences in the prosthetic aftercare over a follow-up period of 5 and even over 10 years (Meijer et al. 2004; Meijer et al. 2009). The minimal number of removable implant-supported dentures, however, in the present study does not allow drawing any conclusions. The frequency of screw-loosening have been reported to be $8.8 \%$ for single crowns (Jung et al. 2012) and $5.3 \%$ for multi-unit reconstructions (Pjetursson et al. 2012b). One might speculate that the relatively high rate of screw-loosenings ( $15.3 \%$ for group S1 and $0.0 \%$ for group S2 resulting in an overall rate of $6.2 \%$ ) was associated with the use of an intermediate abutment (for the one-piece implant system). In all fixed reconstructions, this intermediate abutment was connected to the implant 
and the final reconstruction then screwed on top with a much lower torque. A retrospective analysis of the same one-piece implant system and intermediate abutments used for singletooth components found an $8.7 \%$ incidence rate of occlusal screw loosening at 6 months (Levine et al. 1997). Interestingly, the same research group reported a massive increase of occlusal screw loosening up to $22.2 \%$ after 2 or more years in function (Levine et al. 1999).

In daily practice, clinicians normally have to choose one implant system, which they will then use for all indications, patients and sites. The outcomes of the present study reflect that both implant systems can be used for fixed and removable reconstructions, for a variety of indications, in partially and fully edentulous patients, for single crowns and multi-unit reconstructions. Survival and complications rates were well within the magnitude of other clinical trials using often more strict inclusion criteria and highly limited indications. From a strictly scientific point of view, the information derived from the present RCT comparing two implant systems must, however, be interprented with caution due to the asymmetric distribution of the implants and the heterogeneity of the reconstructions. 


\section{Conclusions}

Both implant systems reveal high survival rates on the implant and prosthetic level over an observation period of 4-6 years without significant differences between the two groups. Apart from marginal bone level changes (in favor of the one-piece implant system), biological, and technical outcomes did not reveal significant differences. 


\section{Acknowledgements and conflict of interest}

The authors would like to acknowledge Prof. Dr. Jürg Hüsler for his support in the statistical analysis of the data. This study was funded by the Clinic of Fixed and Removable Prosthodontics and Dental Material Science, Center of Dental Medicine, University of Zurich, Zurich, Switzerland. The authors report no conflict of interest regarding this clinical study. 


\section{References}

Adell, R., Hansson, B. O., Branemark, P. I. \& Breine, U. (1970) Intra-osseous anchorage of dental prostheses. li. Review of clinical approaches. Scandinavian Journal of Plastic and Reconstructive Surgery 4: 19-34.

Adell, R., Lekholm, U., Rockler, B. \& Branemark, P. I. (1981) A 15-year study of osseointegrated implants in the treatment of the edentulous jaw. International Journal of Oral Surgery 10: 387-416.

Ainamo, J. \& Bay, I. (1975) Problems and proposals for recording gingivitis and plaque. International Dental Journal 25: 229-235.

Albrektsson, T., Zarb, G., Worthington, P. \& Eriksson, A. R. (1986) The long-term efficacy of currently used dental implants: A review and proposed criteria of success. International Journal of Oral and Maxillofacial Implants 1: 11-25.

Andersson, B., Glauser, R., Maglione, M. \& Taylor, A. (2003) Ceramic implant abutments for shortspan fpds: A prospective 5-year multicenter study. International Journal of Prosthodontics 16: 640646.

Astrand, P., Engquist, B., Anzen, B., Bergendal, T., Hallman, M., Karlsson, U., Kvint, S., Lysell, L. \& Rundcranz, T. (2004) A three-year follow-up report of a comparative study of iti dental implants and branemark system implants in the treatment of the partially edentulous maxilla. Clinical Implant Dentistry and Related Research 6: 130-141.

Astrand, P., Engquist, B., Dahlgren, S., Engquist, E., Feldmann, H. \& Grondahl, K. (1999) Astra tech and branemark system implants: A prospective 5-year comparative study. Results after one year. Clinical Implant Dentistry and Related Research 1: 17-26.

Behneke, A., Behneke, N. \& d'Hoedt, B. (2000) The longitudinal clinical effectiveness of iti solidscrew implants in partially edentulous patients: A 5-year follow-up report. International Journal of Oral and Maxillofacial Implants 15: 633-645.

Belser, U. C., Buser, D., Hess, D., Schmid, B., Bernard, J. P. \& Lang, N. P. (1998) Aesthetic implant restorations in partially edentulous patients--a critical appraisal. Periodontology 2000 17: 132-150. 
Bragger, U., Aeschlimann, S., Burgin, W., Hammerle, C. H. \& Lang, N. P. (2001) Biological and technical complications and failures with fixed partial dentures (fpd) on implants and teeth after four to five years of function. Clinical Oral Implants Research 12: 26-34.

Branemark, P. I., Adell, R., Breine, U., Hansson, B. O., Lindstrom, J. \& Ohlsson, A. (1969a) Intraosseous anchorage of dental prostheses. I. Experimental studies. Scandinavian Journal of Plastic and Reconstructive Surgery 3: 81-100.

Branemark, P. I., Adell, R., Breine, U., Hansson, B. O., Lindstrom, J. \& Ohlsson, A. (1969b) Intraosseous anchorage of dental prostheses. I. Experimental studies. Scandinavian Journal of Plastic and Reconstructive Surgery 3: 81-100.

Branemark, P. I., Adell, R. \& Hansson, B. O. (1971) [reconstruction of jaws and intraosseous anchorage of dental prosthesis]. Tandlakartidningen 63: 486-497.

Branemark, P. I., Hansson, B. O., Adell, R., Breine, U., Lindstrom, J., Hallen, O. \& Ohman, A. (1977a) Osseointegrated implants in the treatment of the edentulous jaw. Experience from a 10year period. Scandinavian Journal of Plastic and Reconstructive Surgery. Supplementum 16: 1132.

Branemark, P. I., Hansson, B. O., Adell, R., Breine, U., Lindstrom, J., Hallen, O. \& Ohman, A. (1977b) Osseointegrated implants in the treatment of the edentulous jaw. Experience from a 10year period. Scandinavian Journal of Plastic and Reconstructive Surgery. Supplementum 16: 1132.

Buser, D., Mericske-Stern, R., Bernard, J. P., Behneke, A., Behneke, N., Hirt, H. P., Belser, U. C. \& Lang, N. P. (1997) Long-term evaluation of non-submerged iti implants. Part 1: 8-year life table analysis of a prospective multi-center study with 2359 implants. Clinical Oral Implants Research 8: 161-172.

Chappuis, V., Buser, R., Bragger, U., Bornstein, M. M., Salvi, G. E. \& Buser, D. (2013) Long-term outcomes of dental implants with a titanium plasma-sprayed surface: A 20-year prospective case series study in partially edentulous patients. Clinical Implant Dentistry and Related Research 15: 780-790.

Derks, J., Hakansson, J., Wennstrom, J. L., Tomasi, C., Larsson, M. \& Berglundh, T. (2015) Effectiveness of implant therapy analyzed in a swedish population: Early and late implant loss. Journal of Dental Research 94: 44S-51S. 
Derks, J., Schaller, D., Hakansson, J., Wennstrom, J. L., Tomasi, C. \& Berglundh, T. (2016) Effectiveness of implant therapy analyzed in a swedish population: Prevalence of peri-implantitis. Journal of Dental Research 95: 43-49.

Ericsson, I., Nilner, K., Klinge, B. \& Glantz, P. O. (1996) Radiographical and histological characteristics of submerged and nonsubmerged titanium implants. An experimental study in the labrador dog. Clinical Oral Implants Research 7: 20-26.

Ericsson, I., Randow, K., Glantz, P. O., Lindhe, J. \& Nilner, K. (1994) Clinical and radiographical features of submerged and nonsubmerged titanium implants. Clinical Oral Implants Research 5: 185-189.

Esposito, M., Ekestubbe, A. \& Grondahl, K. (1993) Radiological evaluation of marginal bone loss at tooth surfaces facing single branemark implants. Clinical Oral Implants Research 4: 151-157.

Esposito, M., Grusovin, M. G., Coulthard, P., Thomsen, P. \& Worthington, H. V. (2005) A 5-year follow-up comparative analysis of the efficacy of various osseointegrated dental implant systems: A systematic review of randomized controlled clinical trials. International Journal of Oral and Maxillofacial Implants 20: 557-568.

Hammerle, C. H., Bragger, U., Burgin, W. \& Lang, N. P. (1996) The effect of subcrestal placement of the polished surface of iti implants on marginal soft and hard tissues. Clinical Oral Implants Research 7: 111-119.

Jemt, T. (1997) Regeneration of gingival papillae after single-implant treatment. International Journal of Periodontics and Restorative Dentistry 17: 326-333.

Jung, R. E., Jones, A. A., Higginbottom, F. L., Wilson, T. G., Schoolfield, J., Buser, D., Hammerle, C. H. \& Cochran, D. L. (2008a) The influence of non-matching implant and abutment diameters on radiographic crestal bone levels in dogs. Journal of Periodontology 79: 260-270.

Jung, R. E., Pjetursson, B. E., Glauser, R., Zembic, A., Zwahlen, M. \& Lang, N. P. (2008b) A systematic review of the 5-year survival and complication rates of implant-supported single crowns. Clinical Oral Implants Research 19: 119-130.

Jung, R. E., Zembic, A., Pjetursson, B. E., Zwahlen, M. \& Thoma, D. S. (2012) Systematic review of the survival rate and the incidence of biological, technical, and aesthetic complications of single crowns on implants reported in longitudinal studies with a mean follow-up of 5 years. Clinical Oral Implants Research 23 Suppl 6: 2-21. 
Levine, R. A., Clem, D. S., 3rd, Wilson, T. G., Jr., Higginbottom, F. \& Saunders, S. L. (1997) A multicenter retrospective analysis of the iti implant system used for single-tooth replacements: Preliminary results at 6 or more months of loading. International Journal of Oral and Maxillofacial Implants 12: 237-242.

Levine, R. A., Clem, D. S., 3rd, Wilson, T. G., Jr., Higginbottom, F. \& Solnit, G. (1999) Multicenter retrospective analysis of the iti implant system used for single-tooth replacements: Results of loading for 2 or more years. International Journal of Oral and Maxillofacial Implants 14: 516-520.

Meijer, H. J., Batenburg, R. H., Raghoebar, G. M. \& Vissink, A. (2004) Mandibular overdentures supported by two branemark, imz or iti implants: A 5-year prospective study. Journal of Clinical Periodontology 31: 522-526.

Meijer, H. J., Raghoebar, G. M., Batenburg, R. H. \& Vissink, A. (2009) Mandibular overdentures supported by two branemark, imz or iti implants: A ten-year prospective randomized study. Journal of Clinical Periodontology 36: 799-806.

Merickse-Stern, R., Aerni, D., Geering, A. H. \& Buser, D. (2001) Long-term evaluation of nonsubmerged hollow cylinder implants. Clinical and radiographic results. Clinical Oral Implants Research 12: 252-259.

Moberg, L. E., Kondell, P. A., Sagulin, G. B., Bolin, A., Heimdahl, A. \& Gynther, G. W. (2001) Branemark system and iti dental implant system for treatment of mandibular edentulism. A comparative randomized study: 3-year follow-up. Clinical Oral Implants Research 12: 450-461.

Mombelli, A. \& Lang, N. P. (1994) Clinical parameters for the evaluation of dental implants. Periodontology 2000 4: 81-86.

O'Leary, T. J., Drake, R. B. \& Naylor, J. E. (1972) The plaque control record. Journal of Periodontology 43: 38.

Ortorp, A. \& Jemt, T. (2008) Laser-welded titanium frameworks supported by implants in the partially edentulous mandible: A 10 -year comparative follow-up study. Clinical Implant Dentistry and Related Research 10: 128-139.

Pinholt, E. M. (2003) Branemark and iti dental implants in the human bone-grafted maxilla: A comparative evaluation. Clinical Oral Implants Research 14: 584-592. 
Pjetursson, B. E., Helbling, C., Weber, H. P., Matuliene, G., Salvi, G. E., Bragger, U., Schmidlin, K., Zwahlen, M. \& Lang, N. P. (2012a) Peri-implantitis susceptibility as it relates to periodontal therapy and supportive care. Clinical Oral Implants Research 23: 888-894.

Pjetursson, B. E., Thoma, D., Jung, R., Zwahlen, M. \& Zembic, A. (2012b) A systematic review of the survival and complication rates of implant-supported fixed dental prostheses (fdps) after a mean observation period of at least 5 years. Clinical Oral Implants Research 23 Suppl 6: 22-38.

Ramfjord, S. P. (1974) Indexes for measurement of loss of periodontium. Journal of Periodontal Research: 78-88.

Renvert, S., Roos-Jansaker, A. M. \& Claffey, N. (2008) Non-surgical treatment of peri-implant mucositis and peri-implantitis: A literature review. Journal of Clinical Periodontology 35: 305-315.

Scacchi, M. (2000) The development of the iti dental implant system. Part 1: A review of the literature. Clinical Oral Implants Research 11 Suppl 1: 8-21.

Scacchi, M., Merz, B. R. \& Schar, A. R. (2000) The development of the iti dental implant system. Part 2: 1998-2000: Steps into the next millennium. Clinical Oral Implants Research 11 Suppl 1: 2232.

Schroeder, A., Pohler, O. \& Sutter, F. (1976) [tissue reaction to an implant of a titanium hollow cylinder with a titanium surface spray layer]. SSO: Schweizerische Monatsschrift fur Zahnheilkunde 86: 713-727.

Schroeder, A., Stich, H., Straumann, F. \& Sutter, F. (1978) [the accumulation of osteocementum around a dental implant under physical loading]. SSO: Schweizerische Monatsschrift fur Zahnheilkunde 88: 1051-1058.

Tarnow, D., Elian, N., Fletcher, P., Froum, S., Magner, A., Cho, S. C., Salama, M., Salama, H. \& Garber, D. A. (2003) Vertical distance from the crest of bone to the height of the interproximal papilla between adjacent implants. Journal of Periodontology 74: 1785-1788.

Thoma, D. S., Sanz Martin, I., Benic, G. I., Roos, M. \& Hammerle, C. H. (2014) Prospective randomized controlled clinical study comparing two dental implant systems: Demographic and radiographic results at one year of loading. Clinical Oral Implants Research 25: 142-149. 


\section{Tables legend}

Table 1: Type of augmentation and type of reconstructions on the implant level for both systems, S1= one-piece (Straumann Tissue Level Implants, Institut Straumann, Basel, Switzerland) and S2= two-piece dental implants (Brånemark MkIII or MkIV, Nobel Biocare, Zurich, Switzerland); guided bone regeneration (GBR), some implants received both primary and simultaneous augmentation procedures; single crowns (SC), 2-unit cantilevered FDP (2FDP), splinted single crowns and implant-borne multi-unit reconstructions without cantilever (FDP), cantilevered splinted single crowns and implant-borne multi-unit reconstructions (cFDP), toothimplant supported prostheses (TISP's), implant-supported removable dentures (ISRD's). The numbers in parentheses display the number of implants.

Table 2: Marginal bone level (MBL) at baseline and at FU-5 and marginal bone level alterations between baseline and FU-5. A. Implant-level analysis of MBL at baseline and at FU-5 with means, SD's, medians and quartiles. $\mathrm{nBL}=$ number of implants at baseline; $\mathrm{n} 5 \mathrm{y}=$ number of implants at FU-5. B. Patient-level analysis of inter-group comparisons between S1 and S2 at baseline and at FU-5; p-values between the groups for each time-point. C. Patient-level analysis of MBL changes over time with means, standard deviations (SD) and p-values within the groups. $\mathrm{nBL}=$ number of patients at baseline; $\mathrm{n} 5 \mathrm{y}=$ number of patients at $\mathrm{FU}-5 ; \mathrm{p}$-values within the groups over time.

$\mathrm{nS} 1=$ number of patients in group $\mathrm{S} 1 ; \mathrm{nS} 2=$ number of patients in group $\mathrm{S} 2 . \mathrm{S} 1=$ one-piece (Straumann Tissue Level Implants, Institut Straumann, Basel, Switzerland) and S2= two-piece dental implants (Brånemark MkIII or MkIV, Nobel Biocare, Zurich, Switzerland).

Table 3: Clinical parameters for both implant systems (S1 and S2) at baseline and at FU-5. Implant-level analysis with with means, standard deviations (SD), medians and quartiles. $\mathrm{nBL}=$ number of implants at baseline; $\mathrm{n} 5 \mathrm{y}=$ number of implants at $\mathrm{FU}-5 . \mathrm{S} 1=$ one-piece (Straumann Tissue Level Implants, Institut Straumann, Basel, Switzerland) and S2= two-piece 
dental implants (Brånemark MkIII or MkIV, Nobel Biocare, Zurich, Switzerland). PPD (probing pocket depth), PII (plaque index), BOP (bleeding on probing), KT (keratinized tissue)

Table 4: Esthetic and further outcome measures at one year and at FU-5. S1= one-piece (Straumann Tissue Level Implants, Institut Straumann, Basel, Switzerland) and S2= two-piece dental implants (Brånemark MkIII or MkIV, Nobel Biocare, Zurich, Switzerland) 


\begin{tabular}{|l|c|c|c|c|c|c|c|c|c|c|} 
& \multicolumn{4}{|c|}{ Type of augmentation } & \multicolumn{4}{c|}{ Type of reconstruction and respective number of implants } \\
\hline $\begin{array}{c}\text { augmen } \\
\text { tation }\end{array}$ & $\begin{array}{c}\text { Simulta } \\
\text { neous } \\
\text { GBR }\end{array}$ & $\begin{array}{c}\text { Primary } \\
\text { bone } \\
\text { augmen } \\
\text { tation } \\
\text { autoge } \\
\text { nous } \\
\text { bone } \\
\text { block) }\end{array}$ & $\begin{array}{c}\text { Primary } \\
\text { sinus } \\
\text { elevatio } \\
\mathbf{n}\end{array}$ & $\begin{array}{c}\text { Simultan } \\
\text { eous } \\
\text { sinus } \\
\text { elevation }\end{array}$ & SC & 2FDP & FDP & cFDP & TISP's & ISRD \\
\hline S1 & 11 & 44 & 6 & 4 & 10 & $21(21)$ & $1(1)$ & $11(23)$ & $4(8)$ & $3(3)$ \\
\hline S2 & 17 & 49 & 6 & 9 & 12 & $25(25)$ & $2(2)$ & $20(42)$ & $2(5)$ & $4(4)$ \\
\hline
\end{tabular}

Table 1 


\begin{tabular}{|c|c|c|c|c|c|c|c|c|c|c|c|}
\hline \multirow{2}{*}{$\begin{array}{l}\text { A) } \\
\text { Variable }\end{array}$} & \multirow{2}{*}{ Time } & \multicolumn{5}{|c|}{$S 1(n B L=65 ; n=57)$} & \multicolumn{5}{|c|}{$S 2(n B L=86 ; n 5 y=85)$} \\
\hline & & Mean & SD ( $( \pm)$ & Lower $\mathbf{Q}$ & Median & Upper Q & Mean & SD ( $( \pm)$ & Lower Q & Median & Upper Q \\
\hline MBL & $\begin{array}{c}\text { Baseline } \\
\text { FU-5 }\end{array}$ & $\begin{array}{l}0.61 \mathrm{~mm} \\
0.62 \mathrm{~mm}\end{array}$ & $\begin{array}{l}0.82 \mathrm{~mm} \\
0.77 \mathrm{~mm}\end{array}$ & $\begin{array}{l}0.14 \mathrm{~mm} \\
0.16 \mathrm{~mm}\end{array}$ & $\begin{array}{l}0.51 \mathrm{~mm} \\
0.49 \mathrm{~mm}\end{array}$ & $\begin{array}{l}0.96 \mathrm{~mm} \\
0.93 \mathrm{~mm}\end{array}$ & $\begin{array}{l}1.07 \mathrm{~mm} \\
1.39 \mathrm{~mm}\end{array}$ & $\begin{array}{l}0.51 \mathrm{~mm} \\
0.44 \mathrm{~mm}\end{array}$ & $\begin{array}{l}0.82 \mathrm{~mm} \\
1.12 \mathrm{~mm}\end{array}$ & $\begin{array}{l}1.02 \mathrm{~mm} \\
1.35 \mathrm{~mm}\end{array}$ & $\begin{array}{l}1.23 \mathrm{~mm} \\
1.63 \mathrm{~mm}\end{array}$ \\
\hline
\end{tabular}

\begin{tabular}{l|c|c|c|c} 
(B) & Baseline (nS1= 30; nS2= 30) & P-Value & FU-5 (nS1= 26; nS2= 30) & P-Value \\
\hline MBL S1 vs. S2 & $-0.485 \mathrm{~mm}(\mathrm{SD} \pm 0.171)$ & 0.0722 & $-0.683 \mathrm{~mm}(\mathrm{SD} \pm 0.173)$ & 0.0014 \\
\hline
\end{tabular}

\begin{tabular}{l|c|c|c|c} 
(C) & $\mathbf{S 1}(\mathbf{n B L}=\mathbf{3 0} ; \mathbf{n 5 y}=\mathbf{2 6})$ & P-Value & $\mathbf{S 2}(\mathbf{n B L}=\mathbf{3 0} ; \mathbf{n 5 y = 3 0 )}$ & $\mathbf{P}-\mathbf{V a l u e}$ \\
\hline $\begin{array}{l}\text { MBL change Baseline - } \\
\text { FU-5 }\end{array}$ & $0.12 \mathrm{~mm}(\mathrm{SD} \pm 0.086)$ & 1.000 & $0.32 \mathrm{~mm}(\mathrm{SD} \pm 0.0713)$ & 0.0002 \\
\hline
\end{tabular}

Table 2 


\begin{tabular}{|c|c|c|c|c|c|c|c|c|c|c|c|}
\hline \multirow{2}{*}{ Variable } & \multirow{2}{*}{ Time } & \multicolumn{5}{|c|}{$S 1(n B L=65 ; n 5 y=57)$} & \multicolumn{5}{|c|}{$S 2(n B L=86 ; n 5 y=85)$} \\
\hline & & Mean & SD ( $( \pm)$ & Lower Q & Median & Upper Q & Mean & SD ( $( \pm)$ & Lower Q & Median & Upper Q \\
\hline PPD & $\begin{array}{c}\text { Baseline } \\
\text { FU-5 }\end{array}$ & $\begin{array}{l}3.04 \mathrm{~mm} \\
3.45 \mathrm{~mm}\end{array}$ & $\begin{array}{l}0.66 \mathrm{~mm} \\
0.80 \mathrm{~mm}\end{array}$ & $\begin{array}{c}2.67 \mathrm{~mm} \\
2.83 \mathrm{~mm}\end{array}$ & $\begin{array}{l}3.00 \mathrm{~mm} \\
3.33 \mathrm{~mm}\end{array}$ & $\begin{array}{l}3.33 \mathrm{~mm} \\
3.67 \mathrm{~mm}\end{array}$ & $\begin{array}{l}2.98 \mathrm{~mm} \\
3.36 \mathrm{~mm}\end{array}$ & $\begin{array}{l}0.65 \mathrm{~mm} \\
0.93 \mathrm{~mm}\end{array}$ & $\begin{array}{l}2.67 \mathrm{~mm} \\
2.83 \mathrm{~mm}\end{array}$ & $\begin{array}{l}2.83 \mathrm{~mm} \\
3.17 \mathrm{~mm}\end{array}$ & $\begin{array}{l}3.00 \mathrm{~mm} \\
3.83 \mathrm{~mm}\end{array}$ \\
\hline PII & $\begin{array}{c}\text { Baseline } \\
\text { FU-5 }\end{array}$ & $\begin{array}{l}14.5 \% \\
21.0 \%\end{array}$ & $\begin{array}{l}26.2 \% \\
30.0 \%\end{array}$ & $\begin{array}{l}0 \% \\
0 \%\end{array}$ & $\begin{array}{l}0 \% \\
0 \%\end{array}$ & $\begin{array}{l}18.7 \% \\
31.0 \%\end{array}$ & $\begin{array}{l}11.9 \% \\
21.0 \%\end{array}$ & $\begin{array}{l}19.9 \% \\
28.0 \%\end{array}$ & $\begin{array}{l}0 \% \\
0 \%\end{array}$ & $\begin{array}{c}0 \% \\
10 \%\end{array}$ & $\begin{array}{l}16.6 \% \\
33.0 \%\end{array}$ \\
\hline BOP & $\begin{array}{c}\text { Baseline } \\
\text { FU-5 }\end{array}$ & $\begin{array}{l}30.9 \% \\
41.0 \%\end{array}$ & $\begin{array}{l}26.7 \% \\
34.0 \%\end{array}$ & $\begin{array}{l}16.6 \% \\
13.0 \%\end{array}$ & $\begin{array}{c}21.8 \% \\
25 \%\end{array}$ & $\begin{array}{l}43.7 \% \\
75.0 \%\end{array}$ & $\begin{array}{l}28.0 \% \\
31.0 \%\end{array}$ & $\begin{array}{l}22.4 \% \\
23.0 \%\end{array}$ & $\begin{array}{c}5.0 \% \\
15.0 \%\end{array}$ & $\begin{array}{l}25 \% \\
28 \%\end{array}$ & $\begin{array}{l}45.8 \% \\
50.0 \%\end{array}$ \\
\hline $\mathbf{K T}$ & FU-5 & $1.92 \mathrm{~mm}$ & $1.68 \mathrm{~mm}$ & $0.0 \mathrm{~mm}$ & $2.0 \mathrm{~mm}$ & $3.0 \mathrm{~mm}$ & $1.99 \mathrm{~mm}$ & $1.52 \mathrm{~mm}$ & $1.0 \mathrm{~mm}$ & $2.0 \mathrm{~mm}$ & $3.0 \mathrm{~mm}$ \\
\hline
\end{tabular}

Table 3 


\begin{tabular}{l|c|c|c|c|} 
& \multicolumn{2}{|c|}{$\mathbf{1 y}$} \\
\hline Modified papilla index (Jemt 1997) $\leq 2$ & $\mathbf{S 1}$ & $\mathbf{S 2}$ & $\mathbf{S 1}$ & $\mathbf{S 2}$ \\
\hline Shimmering of the implant through the mucosa & 32 & 37 & 24 & 59 \\
\hline Visibility of the crown margin & 6 & 12 & 12 & 28 \\
\hline Level of the margo mucosae compared to the contralateral site & 22 & 22 & 30 & 42 \\
\hline
\end{tabular}

Table 4 